\title{
Sistema de conducción cardíaca
}

Heart conduction system

Maritere Morales-Aguilar $^{a^{*}}$, Carlos E. García-de-Jesús ${ }^{a}$

\begin{abstract}
:
The rhythmic conduction of the human heart has a specialized system of fibers that allow the muscle to self-excite from the generation of the electrical impulse initiated in the sinoatrial node that runs through the atria and ends in the ventricles through the Purkinje fibers. The mechanism is made possible by the phases of the action potential (depolarization, initial repolerization, plateau, rapid repolarization and resting potential) that occur in the myocardium.
\end{abstract}

\section{Keywords:}

Cardiac conduction, action potential, Purkinje system, myocardial contraction

\section{Resumen:}

La conducción rítmica del corazón humano cuenta con un sistema especializado de fibras que permiten que el músculo pueda autoexcitarse a partir de la generación del impulso eléctrico iniciado en el nodo sinoauricular que recorre las aurículas y termina en los ventrículos a través de las fibras de Purkinje. El mecanismo se hace posible mediante las fases del potencial de acción (despolarización, repolarización inicial, meseta, repolarización rápida y potencial de reposo) que ocurren en el miocardio.

\section{Palabras Clave:}

Conducción cardíaca, potencial de acción, sistema de Purkinje, contracción miocárdica

a Escuela Superior Tepeji del Rio, Licenciatura Médico Cirujano, Universidad Autónoma del Estado de Hidalgo, Av. Del Maestro No 4, 


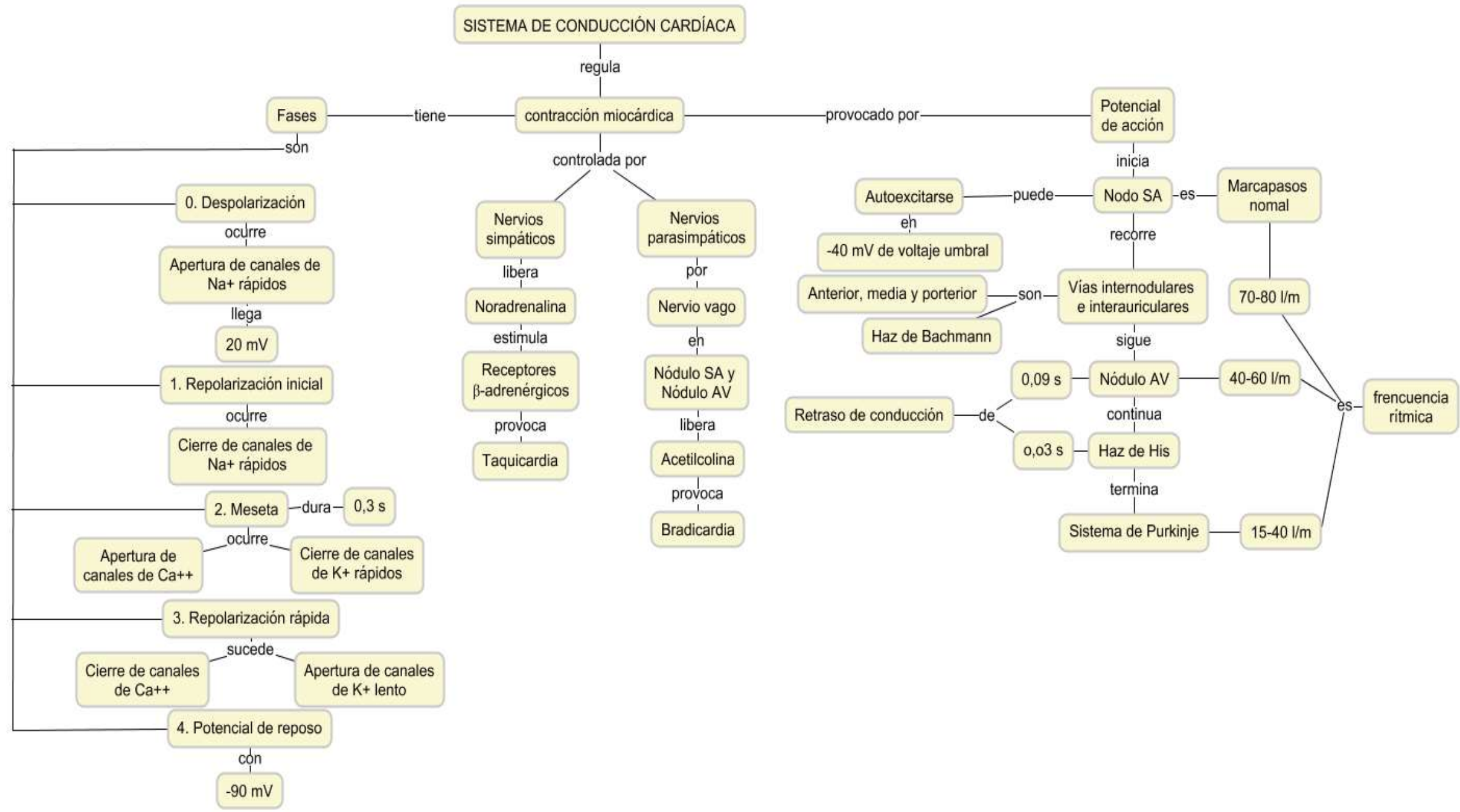

\section{Referencias}

[1] Guyton, A. \& Hall, J. (2016). Excitación rítmica del corazón. En Tratado de Fisiología médica (pp. 123-129). España: Elsevier.

[2] Ramírez, F. (2009). Fisiología cardíaca. En Ciencias básicas Revista médica MD. Septiembre 19, 2019 en: https://www.medigraphic.com/pdfs/revmed/md-2009/md093d.pdf

[3] Murillo, M., Cabrera, J., Pizarrot, G. \& Sanchez, D. (2011). Anatomía del tejido especializado de conducción cardiaco.Su interés en la cardiología intervencionista. En Revista Iberoamericana de Arritmología ria. Septiembre 19,2019 en: http://www.riaonline.com/webapp/uploads/141_layouted_dami\%C3\%A1n_s\%C3\%A1nchez-quintana-_id-141_20110617.pdf 